\title{
Diagnostic Accuracy of CT Readings of Coin Lesions in the Lung as Compared with Transthoracic CT-Guided Needle Biopsy Results
}

\author{
Diagnostische Genauigkeit der CT bei intrapulmonalen Rundherden im Vergleich \\ zu den histopathologischen Resultaten der CT-gesteuerten Biopsie
}

Authors

Institution
A. Maataoui, T. J. Vogl, V. Jacobi, M. F. Khan

Institute for Diagnostic and Interventional Radiology, Johann Wolfgang Goethe University, Frankfurt/Main, Germany received 30.4 .2012 accepted after revision 28. 5. 2012

\section{Bibliography}

Dol http://dx.doi.org/

10.1055/s-0032-1309978

Pneumologie 2012; 66: 432-436

(c) Georg Thieme Verlag KG Stuttgart · New York ISSN 0934-8387

Corresponding author Adel Maataoui, MD

Institute for Diagnostic and Interventional Radiology Johann Wolfgang Goethe University, Frankfurt Theodor-Stern-Kai 7 60590 Frankfurt am Main Germany

adel.maataoui@gmx.de

\section{Abstract \\ $\nabla$}

Background: The aim of this study was to compare chest $\mathrm{CT}$ film reading results with histopathological results after CT-guided transthoracic needle biopsy of the lung. In addition, lung lesion morphology was evaluated and compared with the nature of the lesions.

Patients and Methods: Pulmonary lesions of 133 patients who underwent chest CT were retrospectively grouped into benign, malignant or uncertain. All patients underwent CT-guided transthoracic biopsy. Results of CT diagnosis and histopathological evaluation were compared. In addition, CT features such as size, borders, shape and presence of necrosis were assessed and compared with histopathological results.

Results: In 129 patients adequate specimens were obtained. Comparison of CT diagnosis with the histopathological results yielded the following results for chest CT: sensitivity $95 \%$, specificity $43 \%$, positive predictive value $83 \%$, and negative predictive value $75 \%$. Lesions with spiculated margins turned out to be associated with a significantly higher number of malignant lesions than lesions with smooth or blurred margins $(\mathrm{p}<$ 0.05 ). Lesions size, lesion shape as well as the presence of necrosis showed no significant relation to nature of the lesions ( $p>0.05)$.

Conclusion: Radiological assessment of pulmonary lesions alone is not sufficient. the specificity of chest CT is not sufficient to make a definitive diagnosis, i.e., histological verification is still needed for further investigation in a large number of cases. Only lesions with spiculated margins showed a significantly higher number of malignant degenerations in histological evaluation.

\section{Zusammenfassung \\ $\nabla$}

Hintergrund: Zum Vergleich CT-morphologischer Befunde fokaler Lungenherde mit histopathologischen Resultaten der CT-gesteuerten Biopsie. Zusätzlich erfolgte die Auswertung bildmorphologischer Kriterien und deren Vergleich mit der histopathologischen Dignität der Läsionen.

Patienten und Methoden: Computertomografisch detektierte Lungenherde von 133 Patienten wurden retrospektiv in benigne, maligne und unklare Läsionen eingeteilt. Alle Läsionen wurden CT-gesteuert punktiert. Die Ergebnisse der CT-morphologischen Bildanalyse sowie der histopathologischen Evaluation wurden verglichen. Zusätzlich wurden bildmorphologische Kriterien wie Größe, Berandung, Form und das Vorliegen von Nekrosen erfasst und mit den histopathologischen Resultaten verglichen.

Ergebnisse: 129 Patienten wurden erfolgreich punktiert. Der Vergleich der computertomografischen Diagnose mit den histopathologischen Resultaten ergab für die CT eine Sensitivität von $95 \%$, eine Spezifität von $43 \%$, einen positiven Vorhersagewert von $83 \%$ sowie einen negativen Vorhersagewert von $75 \%$. Läsionen mit spikulierter Berandung waren signifikant häufiger maligne als Läsionen mit glatter oder unscharfer Berandung $(p<0.05)$. Größe, Form oder vorhandene Nekrosen hatten keinen statistisch signifikanten Bezug zur Läsionsdignität ( $p>0.05$ ).

Schlussfolgerung: Die Spezifität der CT des Thorax ist zumeist nicht ausreichend für eine endgültige Diagnosestellung, sodass eine histologische Sicherung in der Mehrzahl der Fälle anzustreben ist. Einzig Läsionen mit spikulierter Berandung zeigten in der histopathologischen Evaluation einen signifikant höheren Anteil maligner Befunde. 


\section{Introduction}

\section{$\nabla$}

Detection of a pulmonary mass on chest X-ray is routinely followed by chest computed tomography (CT) for further investigation. CT provides better information such as exact localization, size, shape, borders and contrast enhancement, involvement of adjacent structures, lymph node involvement and in cases of malignant disease the detection of metastasis. In association with the imaging criteria mentioned above, CT helps to narrow the diagnostic spectrum. Based on its results, decisions for further invasive investigations are undertaken to confirm the imaging diagnosis histologically. CT-guided percutaneous transthoracic needle biopsy of the lung is a well established method in the histological diagnosis of pulmonary lesions [ $1-4]$ and is regarded as a safe procedure with limited morbidity and very rare mortality [1-9]. Pneumothorax and perifocal hemorrhage remain the most frequent complications $[5,6,8,10]$.

Other serious complications such as empyema and seeding of malignant cells into the needle track are rare and should not influence the indications for CT-guided transthoracic needle biopsy [11].

The diagnostic accuracy of this method has been reported and ranges from $64 \%$ to $97 \%[5,9,12-20]$. So far histological CT-guided biopsy results were only compared to results of postsurgical histological examinations or with long-term CT follow-ups. None of the current studies has compared the chest CT imaging diagnosis with the histological results of transthoracic CT-guided biopsy.

The purpose of the present study was to compare our results of chest CT imaging diagnosis with the histological results of transthoracic CT-guided biopsy with regard to specificity, sensitivity, positive and negative predictive values. In addition the morphology of lesions was assessed and correlated with their histopathology.

\section{Material and Methods \\ $\nabla$}

\section{Patients}

84 men and 49 women aged $30-83$ years (mean age 63.4 years) were included in the study. The pulmonary coin lesions were detected as incidental findings during a chest CT which was primarily conducted for other clinical indications. $91 \%$ of the patients were referred to our institution by the various departments of our hospital, $9 \%$ of the patients were referred to us by external physicians. Informed consent was obtained from all patients at least 24 hours before biopsy.

\section{CT scanning and interpretation}

In all patients, chest CT scans were obtained prior to biopsy. CT scans were obtained by using a 16-row MDCT (multidetector computed tomography; Sensation 16, Siemens Medical Systems, Forchheim, Germany). Scanning was performed in caudo-cranial direction using the helical technique, with $1.5 \mathrm{~mm}$ collimation. The exposure parameters for CT scanning were $120 \mathrm{kV}$ and 120 $\mathrm{mAs}$. Each patient received $100 \mathrm{~mL}$ of a non-ionic contrast medium at a flow rate of $3.0 \mathrm{~mL} / \mathrm{sec}$ (Ultravist ${ }^{\circledR} 370 \mathrm{mg} / \mathrm{mL}$; Schering Inc., Berlin, Germany) infused through an 18-gauge intravenous antecubital catheter. All scans were analyzed at a lung window (width 2000 /center -500), soft tissue window (width 450 /center 50 ) and bone window (width $2700 /$ center 700 ). All scans were reconstructed in $5 \mathrm{~mm}$ slice thickness and $2.5 \mathrm{~mm}$ overlap.
Two staff radiologists, who had more than 10 years of experience in chest CT reading, classified all lesions into benign, malignant or uncertain according to the parameters listed below.

Presence of tumour necrosis: Tumour necrosis was described if the evaluated lesion showed a hypodense center after administration of i.v. contrast medium.

Size: Lesion size was determined along the maximum expansion in two planes in a lung window setting using an electric calliper. Lesions $>30 \mathrm{~mm}$ in diameter were classified as malignant whereas lesions $<10 \mathrm{~mm}$ were classified as benign [21]. Lesion size between $11-29 \mathrm{~mm}$ was classified as uncertain.

Shape: The shape of the lesion was classified into round, oval, wedge-shaped and polycyclic. Lesions with concave shaped margins were classified as scar tissue whereas lesions with convex shaped margins were classified as proliferative tissue and therefore suspicious for malignancy [21].

Borders: The borders of the lesion was classified into smooth (benign), blurred (uncertain) and spiculated (malignant).

Presence of calcifications: Pulmonary nodules or masses in which fat or calcification without significant contrast medium enhancement were detected were classified as benign hamarthomas or granulomas [21].

Attenuation values before and after contrast media application: Attenuation values before and after contrast medium injection were measured in a solid part of the lesion. Lesions enhancing less than $15 \mathrm{HU}$ were classified as benign, enhancement $>25 \mathrm{HU}$ as malignant and enhancement between 16 and $25 \mathrm{HU}$ uncertain [21-23].

Decisions in regard to the features and further treatment were made in consensus if the evaluated lesion had varying numbers of benign and malignant features.

\section{Biopsy procedure}

All biopsies were performed under CT guidance by staff radiologists, both of whom had more than 10 years experience in CTguided transthoracic needle biopsy.

Patients were handled in an outpatient setting whenever possible. 135 percutaneous transthoracic needle biopsies were performed in the 133 patients at our hospital. 2 patients underwent biopsy twice, due to insufficient specimen on the first biopsy. Exclusion criteria were lung lesions smaller than $5 \mathrm{~mm}$ in maximum diameter, patients who were not able to follow verbal or visual instructions and patients who refused to give their informed consent. Emphysema was not an exclusion criterion for biopsy.

Before biopsy, coagulation parameters of all patients were checked. It was assured that patients were not taking anticoagulants or aspirin and had normal platelet counts, prothrombin time and activated prothrombin time. Blood sampling was done no longer than 3 days before biopsy. Depending on the location of the lesion procedures were performed with the patient in a prone, supine, or lateral position. No precautions were taken to prevent pneumothorax in terms of patient positioning. Patients were instructed to breathe calmly during the procedure and abstain from talking. Axial images were acquired from the chest before biopsy. Biopsy was monitored by obtaining selected images at the area of interest with $10-\mathrm{mm}$ transverse CT sections. The skin around the puncture site was disinfected with $10 \%$ iodine solution and the area was covered sterilely. $10 \mathrm{~mL}$ of $1 \%$ xylocain were administered subcutaneously as local anesthesia. After skin incision all biopsies were performed with an 18-gauge cutting needle system (Biopsy-Handy ${ }^{\circledR}$, Somatex ${ }^{\circledR}$ Medical Technologies 
Ltd., Teltow, Germany). The cutting needle was manually pushed into the lung lesion and a 20 - $\mathrm{mm}$ long tissue core was retrieved. If possible fissures, pleural effusions and pleural bullae were avoided during biopsy. Before sampling, the aspiration needle position within the lesion was documented by obtaining axial CT images.

Specimens obtained were immediately immersed in $10 \%$ formalin solution and sent for examination to the staff pathologist of our hospital.

Immediately after biopsy a chest $\mathrm{CT}$ scan was done to detect pneumothorax or intrapulmonal hemorrhage. After the procedure patients were placed on a stretcher or bed for 4 hours, with the supervision of a nurse. Four hours after the biopsy chest radiographs were obtained with the patient in an erect position for detection of pneumothorax or hemorrhage. Pneumothorax was treated in symptomatic cases or when the pneumothorax was enlarging as compared to the CT obtained just after biopsy.

\section{Statistical analysis}

Diagnostic accuracy, i.e., true-positive rate, true-negative rate, false-positive rate, false-negative rate, negative predictive value, positive predictive value, sensitivity and specificity were determined.

True positive was defined as a case in which the CT diagnosis of malignant disease was confirmed histologically. True negative was defined as a case in which the initial CT diagnosis of benign disease was confirmed histologically. False positive was defined as a case in which a lesion was classified as not benign in chest CT, i.e., malignant or uncertain, but turned out to be benign in histological work-up. False negative was defined as a case that was classified as benign in chest CT but turned out to be malignant or uncertain in histological work-up.

Statistical analysis was carried out using the BiAS for Windows software package (Version 8.2, 1989-2006, Epsilon Publishers).

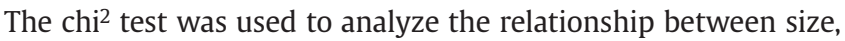
shape, presence of necrosis, borders of the lesions and their histological nature. Differences were considered significant when the $p$ value was below 0.05 .

\section{Results}

Radiological diagnosis using chest CT classified 93 lesions as malignant, 20 lesions as primarily benign and 22 lesions as uncertain. Histological work-up yielded 94 malignant lesions and 35 benign lesions. 6 cases remained uncertain.

From 93 cases diagnosed as malignant on chest CT 15 cases turned out to be benign and 2 were uncertain after histological work-up. From 20 cases diagnosed as benign on chest CT, 5 cases turned out to be malignant. Only 4 out of the 22 cases remained uncertain after histological evaluation. Two cases could not be classified in histological work-up but have been classified as malignant in chest CT $(\bullet$ Table 1$)$.

Out of the 6 cases that remained uncertain after histological evaluation, an insufficient biopsy specimen was sampled in one case, in four cases unrepresentative biopsy specimens were sampled and in another case the suspicious lesion was missed.

95 cases were true positive, 20 cases were false positive, 15 cases were true-negative and 5 cases false negative. The true-positive rate (sensitivity) was $95 \%$, the false-positive rate was $57 \%$, the true-negative rate (specificity) was $43 \%$ and the false-negative
Table 1 Comparison of chest CT diagnosis with histopathological evaluation.

\begin{tabular}{|lllcl} 
& All & Malignant & Benign & Uncertain \\
\hline Chest CT & 135 & 93 & 20 & 22 \\
\hline \multirow{2}{*}{ Histology } & Malignant & $76(82 \%)$ & $5(25 \%)$ & $13(59 \%)$ \\
& Benign & $15(16 \%)$ & $15(75 \%)$ & $5(23 \%)$ \\
& Uncertain & $2(2 \%)$ & 0 & $4(18 \%)$
\end{tabular}

Table 2 Lesion margination and its histopathologic distribution.

\begin{tabular}{lclll} 
Borders & $\mathbf{n}$ & Malignant & Benign & Uncertain \\
\hline Smooth & 68 & 44 & 18 & 6 \\
\hline Blurred & 32 & 18 & 14 & 0 \\
Spiculated & 35 & 32 & 3 & 0 \\
& 135 & 94 & 35 & 6 \\
\hline
\end{tabular}

Table 3 Lesion size and its histopathological distribution.

\begin{tabular}{|lrrrr|}
\hline Size $[\mathbf{c m}]$ & $\mathbf{n}$ & Malignant & Benign & Uncertain \\
\hline$\leq 1$ & 8 & 6 & 0 & 2 \\
\hline$>1-2$ & 33 & 22 & 9 & 2 \\
\hline$>2-3$ & 29 & 21 & 7 & 1 \\
\hline$>3-4$ & 18 & 17 & 1 & 0 \\
\hline$>4-6$ & 29 & 15 & 14 & 0 \\
\hline$>6-10$ & 14 & 11 & 2 & 1 \\
\hline$>10$ & 4 & 2 & 2 & 0 \\
\hline
\end{tabular}

Table 4 Lesion shape and its histopathological distribution.

\begin{tabular}{|lclcl|}
\hline Shape & n & Malignant & Benign & Uncertain \\
\hline Round & 54 & 38 & 10 & 6 \\
\hline Geometric & 19 & 11 & 8 & 0 \\
\hline Oval & 31 & 21 & 10 & 0 \\
\hline Wedge-shaped & 14 & 10 & 4 & 0 \\
\hline Polycyclic & 17 & 14 & 3 & 0 \\
\hline & 135 & 94 & 35 & 6 \\
\hline
\end{tabular}

rate was $5 \%$. The positive predictive value was $83 \%$ and the negative predictive value was 75\% ( Table 1 ).

Lesions with spiculated boundaries turned out to be associated with a significantly higher number of malignant lesions than those with smooth or blurred margins $(\mathrm{p}<0.05)$ with a sensitivity of $100 \%$ and a positive predicitive value of $91 \%$, respectively (- Table 2).

Lesion size, lesion shape as well as the presence of necrosis showed no significant relation to nature of the lesions $(p>0.05)$ (๑ Table 3, Table 4).

\section{Complications}

Three patients required chest tube placement for treatment of pneumothorax. Intrapulmonal hemorrhage requiring further clinical follow-up occurred in 9 patients. Pneumothorax as well as intrapulmonal hemorrhage resolved within a few days without further invasive interventions, either by chest surgery or by interventional radiology. 


\section{Discussion}

\section{$\nabla$}

Because of the high incidence of malignant disease of the chest, and in particular of the lung, every lesion needs to be considered as suspicious until proven otherwise. Therefore biopsy procedures play a major role in the diagnostic cascade in pulmonary disease. This is particularly important when considering the high number of false-positive lesions reported on the largest screening trial NLST (National Lung Screening Trial, 96.4\%) [24]. In the last 3 decades several studies have proved the accuracy and safety of image-guided transthoracic lung biopsy procedures [1 $9,25]$.

Reports about diagnostic accuracy have compared histological CT-guided biopsy results with the results of histological examinations after surgery or with long-term CT follow-ups, i.e., these studies reported efficacies which range from $82 \%$ to $95 \%[5,12$, 16-18].

To the best of our knowledge none of these reports compared chest CT imaging diagnosis with the histological results of transthoracic CT-guided biopsy and, as such we have to discuss our results in the context of studies which used histological examinations after surgery or long-term CT follow-ups as a reference.

In this study we found a sensitivity (95\%) and a positive predictive value $(83 \%)$ similar to those reported by previous studies while specificities and negative predictive values were lower [5, 12, 16-18].

Specificities of up to $100 \%$ as reported by some authors cannot be confirmed by our data $[5,12,16-18]$.

The high rate of false-positive cases in our study results in a specificity of $43 \%$ in chest CT diagnosis. This underlines how important the histological work-up of pulmonary lesions is and clearly shows the limitations of chest CT as sole diagnostic method. Even PET/CT turned out to be not specific enough to abandon tissue confirmation [26]. Data about the value of PET/MRI must still be collected and have not been evaluated as yet.

Potential diagnostic features such as lesion shape, lesion size or the presence of necrosis did not show any relation to the nature of the lesion. Although increasing lesion size was reported [21] to be more likely to be malignant, we cannot confirm this from our data. On the other hand, our data clearly confirm reports by several authors $[21,27-30]$ that lesions with spiculated margins are significantly more likely to be linked to malignancy. $\bullet$ Table 1 shows that chest CT diagnosis remains uncertain in more than $16 \%$ of the cases, i.e., radiological assessment of pulmonary lesions alone is not sufficient. Even though we found high positive predictive value, negative predictive value and specificity, the overall significance is too low to solely rely on chest CT. In the group of uncertain CT diagnosis, 59\% turned out to be malignant after histological evaluation. These results justify that uncertain cases in chest CT are managed as suspicious lesions until proven otherwise. Histological verification helps to reduce the number of uncertain cases significantly $(p<0.05)$ and therefore is still needed for further investigation in a substantial number of cases. Patients benefit from a lower rate of follow-up examinations and a reduction of the associated irradiation. Data from the NSLT [24] and NELSON [31] trials indicate that there is a $20 \%$ or even more lung cancer mortality reduction when using low-dose CT as a screening method in selected patients. Other much smaller studies show no stage shift or reduction in mortality [32]. Although these results are currently controversially discussed [33] they have led to changes in recommendations already [34], thus if they are confirmed they may facilitate the use of CT, but at the same time increase the number of false-positive results leading to further diagnostic investigations.

However, we found a $5 \%$ rate of missed (false-negative) diagnoses for malignant lung tissue, i.e., gross naked eye inspection of the sampled tissue core by the radiologist is not a guarantee for successful biopsy [35]. In cases in which there are discrepancies between CT features, clinical presentation and biopsy results, the biopsy should be repeated.

A limitation of this study was that, due to the retrospective nature of data collection, we had no control over the sample size. In this study we focused on a comparison of chest CT imaging diagnosis with the histological results of transthoracic CT-guided biopsy, therefore data from histological work-up of the surgical specimen or long-term CT follow-up studies were not included in this paper.

Our results confirm clinical practice: The combination of both chest CT imaging and further invasive investigations, such as transthoracic CT-guided biopsy, fiber-optic bronchoscopy or open surgery, are useful measures in patients with pulmonary lesions.

\section{Conflict of interest}

$\nabla$

The authors have no conflict of interest.

\section{References}

1 Li H, Boiselle PM, Shepard JO et al. Diagnostic accuracy and safety of CTguided percutaneous needle aspiration biopsy of the lung: comparison of small and large pulmonary nodules. AJR Am J Roentgenol 1996; 167: 105-109

2 Perlmutt LM, Johnston WW, Dunnick NR. Percutaneous transthoracic needle aspiration: a review. AJR Am J Roentgenol 1989; 152: 451 - 455

3 Stanley JH, Fish GD, Andriole JG et al. Lung lesions: cytologic diagnosis by fine-needle biopsy. Radiology 1987; 162: 389-391

4 Westcott JL. Percutaneous transthoracic needle biopsy. Radiology 1988; 169: 593 - 601

5 Geraghty PR, Kee ST, McFarlane G et al. CT-guided transthoracic needle aspiration biopsy of pulmonary nodules: needle size and pneumothorax rate. Radiology 2003; 229: $475-481$

6 Kazerooni EA, Lim FT, Mikhail A et al. Risk of pneumothorax in CT-guided transthoracic needle aspiration biopsy of the lung. Radiology 1996; 198: 371 - 375

7 Khouri NF, Stitik FP, Erozan YS et al. Transthoracic needle aspiration biopsy of benign and malignant lung lesions. AJR Am J Roentgenol 1985; 144: $281-288$

8 Larscheid RC, Thorpe PE, Scott WJ. Percutaneous transthoracic needle aspiration biopsy: a comprehensive review of its current role in the diagnosis and treatment of lung tumors. Chest 1998; 114: 704-709

9 Tsukada H, Satou T, Iwashima A et al. Diagnostic accuracy of CT-guided automated needle biopsy of lung nodules. AJR Am J Roentgenol 2000; 175: $239-243$

10 Cox JE, Chiles C, McManus CM et al. Transthoracic needle aspiration biopsy: variables that affect risk of pneumothorax. Radiology 1999; 212: $165-168$

11 Muller NL, Bergin CJ, Miller RR et al. Seeding of malignant cells into the needle track after lung and pleural biopsy. Can Assoc Radiol J 1986; 37 : $192-194$

12 Anderson JM, Murchison J, Patel D. CT-guided lung biopsy: factors influencing diagnostic yield and complication rate. Clin Radiol 2003; 58: $791-797$

13 Klein JS, Salomon G, Stewart EA. Transthoracic needle biopsy with a coaxially placed 20-gauge automated cutting needle: results in 122 patients. Radiology 1996; 198: $715-720$

14 Klein JS, Zarka MA. Transthoracic needle biopsy: an overview. J Thorac Imaging 1997; 12: $232-249$

15 Laurent $F$, Latrabe $V$, Vergier $B$ et al. CT-guided transthoracic needle biopsy of pulmonary nodules smaller than $20 \mathrm{~mm}$ : results with an automated 20-gauge coaxial cutting needle. Clin Radiol 2000; 55: $281-287$ 
16 Lopez Hanninen E, Vogl TJ, Ricke J et al. CT-guided percutaneous core biopsies of pulmonary lesions. Diagnostic accuracy, complications and therapeutic impact. Acta Radiol 2001; 42: 151 - 155

17 Maskell NA, Gleeson FV, Davies RJ. Standard pleural biopsy versus CTguided cutting-needle biopsy for diagnosis of malignant disease in pleural effusions: a randomised controlled trial. Lancet 2003; 361: $1326-1330$

18 Moulton JS, Moore PT. Coaxial percutaneous biopsy technique with automated biopsy devices: value in improving accuracy and negative predictive value. Radiology 1993; 186: 515-522

19 SwischukJL, Castaneda F, Patel JC et al. Percutaneous transthoracic needle biopsy of the lung: review of 612 lesions. J Vasc Interv Radiol 1998; 9: $347-352$

20 Westcott JL, Rao N, Colley DP. Transthoracic needle biopsy of small pulmonary nodules. Radiology 1997; 202: 97-103

21 Abolmaali ND, Vogl TJ. [Modern diagnosis of lung nodules]. Radiologe 2004; 44: $472-483$

$22 \mathrm{Kim}$ TH, Kim SJ, Ryu YH et al. Pleomorphic carcinoma of lung: comparison of CT features and pathologic findings. Radiology 2004; 232: $554-559$

23 Potente $G$, Iacari $V$, Caimi $M$. The challenge of solitary pulmonary nodules: HRCT evaluation. Comput Med Imaging Graph 1997; 21: 39-46

24 Aberle DR, Berg CD, Black WC et al. The National Lung Screening Trial: overview and study design. Radiology 2011; 258: 243-253

25 van Sonnenberg E, Lin AS, Deutsch AL et al. Percutaneous biopsy of difficult mediastinal, hilar, and pulmonary lesions by computed tomographic guidance and a modified coaxial technique. Radiology 1983; 148: $300-302$

$26 \mathrm{OJH}$. Yoo leR, Kim SH et al. Clinical significance of small pulmonary nodules with little or no ${ }^{18} \mathrm{~F}-\mathrm{FDG}$ uptake on PET/CT images of patients with nonthoracic malignancies. J Nucl Med 2007; 48: 15-21
27 Erasmus IJ, Connolly JE, McAdams HP et al. Solitary pulmonary nodules: Part I. Morphologic evaluation for differentiation of benign and malignant lesions. Radiographics 2000; 20: $43-58$

28 Kim H, Kang SJ, Suh GY et al. Predictors for benign solitary pulmonary nodule in tuberculosis-endemic area. Korean J Intern Med 2001; 16: $236-241$

29 Winer-Muram HT, Jennings SG, Tarver RD et al. Volumetric growth rate of stage I lung cancer prior to treatment: serial CT scanning. Radiology 2002; 223: $798-805$

30 Zwirewich CV, Vedal S, Miller RR et al. Solitary pulmonary nodule: highresolution CT and radiologic-pathologic correlation. Radiology 1991; 179: $469-476$

31 van Iersel CA, de Koning HJ, Draisma G et al. Risk-based selection from the general population in a screening trial: selection criteria, recruitment and power for the Dutch-Belgian randomised lung cancer multi-slice CT screening trial (NELSON). Int J Cancer 2007; 120: 868-874

32 Saghir Z, Dirksen A, Ashraf $H$ et al. CT screening for lung cancer brings forward early disease. The randomised Danish Lung Cancer Screening Trial: status after five annual screening rounds with low-dose CT. Thorax 2012; 67: 296 - 301

33 Spiro SG. Screening for lung cancer: we still need to know more. Thorax 2012; 67: 283-285

34 Vogelmeier C, Worth $H$, Pfeifer $M$ et al. [Joint statement of the German Respiratory Society and the German Roentgenological Society on the early detection of lung cancer by low-dose CT]. Pneumologie 2011; 65: $5-6$

35 Yeow KM, See $L C$, Lui KW et al. Risk factors for pneumothorax and bleeding after CT-guided percutaneous coaxial cutting needle biopsy of lung lesions. J Vasc Interv Radiol 2001; 12: $1305-1312$ 